\title{
Evaluation of a Novel Therapeutic Repetitive Transcranial Magnetic Stimulation Technique Optimized for Increased Accessibility in Major Depression
}

\author{
Jean-Philippe Miron ${ }^{\mathrm{a}, \mathrm{b}, \mathrm{c}, \mathrm{d},{ }^{*}}$, Helena Voetterl ${ }^{\mathrm{a} e \mathrm{e}}$, Linsay Fox ${ }^{\mathrm{a}}$, Molly Hyde ${ }^{\mathrm{a}}$, Farrokh Mansouri ${ }^{\mathrm{a}, \mathrm{b}}$, \\ Sinjin Dees ${ }^{f}$, Ryan Zhou ${ }^{a}$, Jack Sheen ${ }^{a, b}$, Véronique Desbeaumes Jodoin ${ }^{d}$, Arsalan Mir- \\ Moghtadaei a,b, Daniel M. Blumberger ${ }^{\text {b,c,g, }}$, Zafiris J. Daskalakis ${ }^{\text {b,c,g,h }}$, Fidel Vila-Rodriguez i, \\ Jonathan Downar ${ }^{a, b, c}$ \\ ${ }^{a}$ Krembil Research Institute, University Health Network, Toronto, ON, Canada; \\ b Institute of Medical Science, Faculty of Medicine, University of Toronto, Toronto, ON, Canada; \\ ${ }^{\mathrm{C}}$ Department of Psychiatry, Faculty of Medicine, University of Toronto, Toronto, ON, Canada; \\ ${ }^{d}$ Centre Hospitalier de l'Université de Montréal (CHUM), Centre de Recherche du CHUM \\ (CRCHUM) et Département de Psychiatrie, Faculté de Médecine, Université de Montréal, \\ Montréal, QC, Canada; \\ e Department of Cognitive Neuroscience, Maastricht University, Maastricht, Limburg,
} Netherlands;

${ }^{\mathrm{f}}$ Faculty of Engineering, McMaster University, Hamilton, ON, Canada;

${ }^{9}$ Temerty Centre for Therapeutic Brain Intervention at the Centre for Addiction and Mental Health, Toronto, ON, Canada;

h Department of Psychiatry, University of California San Diego, San Diego, California, USA;

' Non-Invasive Neurostimulation Therapies Laboratory, Department of Psychiatry, University of British Columbia, Vancouver, BC, Canada.

* Corresponding author: jean-philippe.miron@umontreal.ca, 900 rue Saint-Denis, Office R09422, Montréal, Québec, Canada, H2X OA9

ABSTRACT WORD COUNT: 198

MANUSCRIPT WORD COUNT: 3825 
medRxiv preprint doi: https://doi.org/10.1101/2020.06.15.20132092; this version posted December $15,2020$. The copyright holder for this preprint (which was not certified by peer review) is the author/funder, who has granted medRxiv a license to display the preprint in perpetuity.

It is made available under a CC-BY-NC-ND 4.0 International license .

\section{ABSTRACT}

Although effective in major depressive disorder (MDD), repetitive transcranial magnetic stimulation (rTMS) is costly and complex, limiting accessibility. We thus tested the feasibility of a novel rTMS protocol optimized for scalability. Several novel techniques were explored, such as an open-room setting, large non-focal parabolic coils, and cost-saving custom-built coil arms. We employed a low-frequency (LF) $1 \mathrm{~Hz}$ stimulation protocol (360 pulses per session), delivered on the most affordable FDA-approved device. MDD participants received an initial accelerated rTMS course (arTMS) of 6 sessions/day over 5 days (30 total), followed by a tapering course of daily sessions (up to 25 ) to decrease the odds of relapse. The self-reported Beck Depression Inventory II (BDI-II) was used to measure severity of depression. Forty-eight (48) patients completed the arTMS course. No serious adverse events occurred, and all patients reported manageable pain levels. Response and remission rates were $35.4 \%$ and $27.1 \%$ on the BDI-II, respectively, at the end of the tapering course. Repeated measures ANOVA showed significant changes of BDI-II scores over time. If rTMS could be delivered for lower cost at higher volume, while preserving efficacy, safety and tolerability, it could warrant further investigation of this treatment as a first-line intervention in MDD.

TRIAL REGISTRATION: ClinicalTrials.gov Identifier: NCT04376697

KEYWORDS: TMS, rTMS, $1 \mathrm{~Hz}, \mathrm{LF}$, arTMS, MDD 
medRxiv preprint doi: https://doi.org/10.1101/2020.06.15.20132092; this version posted December 15, 2020. The copyright holder for this preprint (which was not certified by peer review) is the author/funder, who has granted medRxiv a license to display the preprint in perpetuity.

It is made available under a CC-BY-NC-ND 4.0 International license .

\section{INTRODUCTION}

Major depressive disorder (MDD) is a common and disabling illness. Up to $50 \%$ of patients experience a chronic or recurrent course, and 30 to $40 \%$ develop treatment-resistant depression (Lam et al., 2016). Furthermore, although antidepressants offer high convenience and simplicity of administration, discontinuation rates approach $50 \%$ after 3 months of use due to concern over side effects and non-response (Kennedy et al., 2016). Alternative treatments are therefore needed.

Repetitive transcranial magnetic stimulation (rTMS) is recognized as an effective intervention in MDD, with recent studies and meta-analyses reporting response and remission rates of up to $50-55 \%$ and $30-35 \%$, respectively (Milev et al., 2016). rTMS has an advantageous side effect profile, with lower discontinuation rates than medication ( $\sim 5 \%$ vs $\sim 25 \%$ ) (Milev et al., 2016). Unfortunately, its widespread adoption is impeded by several obstacles that limit clinical accessibility.

The main issue concerns high acquisition and operation costs, with average cost per remission estimated to be of up to $\$ 6,146$ in the US (Mendlowitz et al., 2019). This is partly a result of the equipment needed to deliver high-frequency (HF) protocols, as well as the need for continuous 1:1 technician-patient supervision during treatment. Technical challenges stem from the complexity of the treatment, such as the need for precise positioning of the widely used figure-of-eight (Fo8) focal coils over the target region.

Another area that remains to be refined is treatment course optimization. The current treatment paradigm forces patients to travel to a treatment center every day for 6 weeks in order to receive a full 30 session course. This can be discouraging, especially for working individuals and those who have families. Several studies have explored "accelerated" rTMS (arTMS), whereby multiple stimulation sessions are delivered per day to shorten the overall treatment course duration. Several large trials of arTMS have consistently reported similar or better remission and response rates than conventional once-daily rTMS (Baeken, 2018; Baeken et al., 
medRxiv preprint doi: https://doi.org/10.1101/2020.06.15.20132092; this version posted December 15, 2020. The copyright holder for this preprint (which was not certified by peer review) is the author/funder, who has granted medRxiv a license to display the preprint in perpetuity.

It is made available under a CC-BY-NC-ND 4.0 International license .

2013; Dardenne et al., 2018; Desmyter et al., 2016; Duprat et al., 2016; Fitzgerald et al., 2018; George et al., 2014; Holtzheimer et al., 2010; McGirr et al., 2015; Schulze et al., 2017; Sonmez et al., 2019; Williams et al., 2018). Furthermore, the total cumulative number of sessions needed to achieve maximal effect is still debated. So far, findings from large rTMS trials have suggested a plateau in clinical response at $\sim 30$ sessions, on average (Perera et al., 2016). This has recently been challenged by a secondary analysis (Kaster et al., 2019) from the THREE-D trial (Blumberger et al., 2018), demonstrating differences in patients' response trajectories to rTMS. Indeed, some participants were still showing signs of improvement at 30 sessions (not reaching a plateau), suggesting that a treatment extension might be needed in some individuals.

To address these issues, we developed a novel rTMS technique optimized for maximum practicality, scalability and effectiveness, while minimizing costs. We employed a safe, welltolerated low-frequency (LF) $1 \mathrm{~Hz}$ stimulation protocol on the lowest cost FDA-approved devices, delivered via large parabolic coils held by low-cost custom arms enabling simple yet accurate placement, in an open-room setting enabling supervision of multiple simultaneous sessions. We also tested the effects of $1 \mathrm{~Hz}$ arTMS followed by a tapering course of once-daily treatment. These technical refinements are designed to enable the provider to accelerate, increase and maintain treatment response beyond what 'standard of care' rTMS can achieve, while achieving higher patient volumes at lower cost.

We hypothesized that our novel rTMS technique would be safe, well-tolerated and effective, while allowing cost-saving opportunities and therefore increasing accessibility.

\section{METHODS}

\subsection{Participants}

We conducted a prospective, single-arm, open-label feasibility study. Participants were recruited after referral to the Poul Hansen Family Centre for Depression neurostimulation specialty clinic, located at the Toronto Western Hospital, an academic healthcare centre which 
medRxiv preprint doi: https://doi.org/10.1101/2020.06.15.20132092; this version posted December 15, 2020. The copyright holder for this preprint (which was not certified by peer review) is the author/funder, who has granted medRxiv a license to display the preprint in perpetuity.

It is made available under a CC-BY-NC-ND 4.0 International license .

is part of the University Health Network (UHN) in Toronto, Canada. Adult (18-85 years of age) outpatients were included for study participation if they 1) had a Mini International Neuropsychiatric Interview (MINI) confirmed MDD diagnosis (single or recurrent episode) and 2) maintained a stable medication regimen from 4 weeks before treatment start to the end of the study. Exclusion criteria were: 1) history of substance dependence or abuse within the last 3 months; 2) concomitant major unstable medical illness; 3) cardiac pacemaker or implanted medication pump; 4) active suicidal intent; 5) diagnosis of any personality disorder as assessed by a study investigator to be primary and causing greater impairment than MDD; 6) diagnosis of any psychotic disorder; 7) any significant neurological disorder or insult (including, but not limited to: any condition likely to be associated with increased intracranial pressure, space occupying brain lesion, any history of seizure confirmed diagnostically by neurological assessment [except those therapeutically induced by ECT], cerebral aneurysm, Parkinson's disease, Huntington's chorea, dementia, stroke, neurologically confirmed diagnosis of traumatic brain injury, or multiple sclerosis); 8) if participating in psychotherapy must have been in stable treatment for at least 3 months prior to entry into the study (with no anticipation of change in the frequency of therapeutic sessions, or the therapeutic focus over the duration of the study); 9) any clinically significant laboratory abnormality in the opinion of the investigator; 10) a dose of more than lorazepam $2 \mathrm{mg}$ daily (or equivalent) currently (or in the last 4 weeks) or any dose of an anticonvulsant due to the potential to limit rTMS efficacy and 11) any non-correctable clinically significant sensory impairment. All participants provided informed consent and this study was approved by the Research Ethics Board of the University Health Network.

\subsection{Study design and procedure}

Treatment was delivered in an open room setting, allowing up to 4 participants to receive treatment simultaneously, with the help of one or two technicians (Figure 1). This was facilitated by an easy-to-use coil placement system, with the Anchored Articulating Arm (AAA) concept at 
medRxiv preprint doi: https://doi.org/10.1101/2020.06.15.20132092; this version posted December 15, 2020. The copyright holder for this preprint (which was not certified by peer review) is the author/funder, who has granted medRxiv a license to display the preprint in perpetuity.

It is made available under a CC-BY-NC-ND 4.0 International license .

its core (Figure 2). AAAs are made out of readily available camera tripod equipment and are anchored at their base to the corner of the treatment chair. Coils are held securely by a clamp locking it to the AAA, maintaining position until treatment has been completed, at which time they can be easily repositioned out of the way.

rTMS was delivered through MagPro R20 stimulators equipped with parabolic MMC-140 coils (MagVenture, Farum, Denmark). We recently published a case series on the safety, tolerability, and effectiveness of those coils in MDD (Miron et al., 2019). The resting motor threshold (rMT) was determined according to standard clinical practice, with the additional need to use the coil's middle ring for stimulation, where the electromagnetic field strength is at its highest (McClintock et al., 2017; Miron et al., 2019). We used a previously published $1 \mathrm{~Hz}$ rTMS protocol (60 s on and $30 \mathrm{~s}$ off, 6 trains, $8.5 \mathrm{~min}$ total stimulation time, 360 pulses/sessions, $120 \%$ rMT) over the right dorsolateral prefrontal cortex (DLPFC) with the coil centred on the F4 EEG location (right-flipped adjusted BeamF3) (Brunelin et al., 2014; Miron et al., 2019). Treatment consisted of an arTMS course of 6 sessions/day (50 min inter-sessions intervals) over 5 days (on weekdays), thus totalling 30 sessions. After a 1-week gap, arTMS was followed by a tapering course of once-daily stimulation (minimum of 20 , maximum of 25 sessions), 3-5 days per week, to decrease the odds of relapse.

Baseline assessments were completed during the week prior to arTMS initiation and consisted of a clinical assessment by trained research staff, including completion of the selfrated Beck Depression Inventory-II (BDI-II) and clinician-rated Hamilton Rating Scale for Depression 17-item (HRSD-17), cap fitting, and motor threshold calibration. Participants were reassessed at 3 subsequent timepoints: post-acute visits were conducted during the one-week gap following arTMS; post-tapering visits were conducted within 7 days of tapering termination; 1-month follow-up visits were conducted 1-month ( \pm 7 days) after the last tapering session. Participants who missed any sessions of the arTMS course were withdrawn. All participants were encouraged to complete the tapering course. Participants were asked not to change their 
medRxiv preprint doi: https://doi.org/10.1101/2020.06.15.20132092; this version posted December $15,2020$. The copyright holder for this preprint (which was not certified by peer review) is the author/funder, who has granted medRxiv a license to display the preprint in perpetuity.

It is made available under a CC-BY-NC-ND 4.0 International license .

medication regimen throughout the whole treatment period. The study timeline is illustrated in Figure 3.

To study response trajectory during treatment days, participants also completed the BDIII at the beginning of each treatment day before rTMS initiation, where they were queried about any adverse events. Self-rated pain intensity of the rTMS procedure was recorded on a verbal analog scale (VRS - from 0 [no pain] to 10 [intolerable pain]). Moreover, serious adverse events and reasons for treatment discontinuation were recorded when such events occurred.

Stimulation intensity was adaptively titrated upward, aiming to reach the target intensity of $120 \%$ rMT on the first session of treatment, without exceeding maximum tolerable pain. We recorded the number of sessions required to reach $120 \% \mathrm{rMT}$.

\subsection{Outcomes}

Primary outcome measures were response and remission rates on the BDI-II. Secondary outcomes included score changes and percent improvement. These outcomes were also calculated on the HRSD-17. Response was defined as score reductions of $\geq 50 \%$ from baseline. Remission was defined as a score of $\leq 12$ (Riedel et al., 2010) on the BDI-II and $\leq 7$ on the HRSD-17 (Zimmerman et al., 2004). We also analyzed the outcome trajectories using the BDI-II.

\subsection{Statistical analysis}

Descriptive statistics were performed on baseline characteristics (age, sex, comorbid anxiety, age of onset of MDD, duration of current MDD episode, total lifetime number of antidepressant medication trials, total ATHF score and baseline BDI score) utilizing independent samples t-tests (two-tailed) for continuous variables, and Chi-square tests for categorical variables. We also performed repeated measures analyses of variance (ANOVA) on BDI-II 
medRxiv preprint doi: https://doi.org/10.1101/2020.06.15.20132092; this version posted December 15, 2020. The copyright holder for this preprint (which was not certified by peer review) is the author/funder, who has granted medRxiv a license to display the preprint in perpetuity.

It is made available under a CC-BY-NC-ND 4.0 International license .

score at different timepoints to assess the effect of the treatment through time. Planned repeated contrasts were used to make comparisons between the different evaluation times.

\section{RESULTS}

From March 18 to September 27, 2019, 57 participants with MDD were assessed for eligibility, 7 of whom were ineligible or declined to participate. 50 participants were thus enrolled and started the study. Of these, 2 discontinued treatment during arTMS because of lack of perceived efficacy and were lost to follow-up. 48 participants moved on to the tapering course and were thus included in the final analysis. Of these, 3 participants discontinued before having completed at least 20 sessions of the tapering course because of the lack of perceived efficacy. 45 participants thus completed the entire study, and 35 followed up at 1 month (Figure 4).

Table 1 provides the baseline characteristics of the study participants. Mean age was $41.8 \pm 12.2$, with $56.3 \%$ female participants. Mean age of depression onset was $23.8 \pm 10.8$ years old, with average length of current episode $51.7 \pm 78.2$ months. $70.8 \%$ of participants were receiving psychopharmacotherapy during the trial, with $58.3 \%$ taking at least one antidepressant during the study. Average Antidepressant Treatment History Form (ATHF) total score was $4.2 \pm 4.3$. Average number of trials on the ATHF in the current episode was $1.4 \pm 2.6$, with $39 / 48(81.3 \%)$ of participants having had at least one adequate antidepressant trial in their current depressive episode. Comparing baseline characteristics variables between responders and non-responders did not yield any statistically significant differences $(p \geq .05)$.

Safety and tolerability outcomes are presented in Table 2. No serious adverse events $(A E)$ were reported at any point of the study. One patient was withdrawn at session 51 since he reported visual symptoms suggestive of possible retinal detachment but was assessed and cleared by ophthalmology (subsequent diagnosis of migraine equivalent). Overall, $39.6 \%$ of participants reported at least one occurrence of an $\mathrm{AE}$ at some point during treatment, the most 
medRxiv preprint doi: https://doi.org/10.1101/2020.06.15.20132092; this version posted December 15, 2020. The copyright holder for this preprint (which was not certified by peer review) is the author/funder, who has granted medRxiv a license to display the preprint in perpetuity.

It is made available under a CC-BY-NC-ND 4.0 International license .

common one having been headache (22.9\%). All AEs were reported exclusively during the arTMS course, with the exception of the previously mentioned participant with visual symptoms at session 51. Pain ratings went from $5.6 \pm 2.0$ on the first treatment, down to $1.9 \pm 1.9$ on the last treatment. The average rMT was $34.6 \pm 5.7 \%$ of maximum stimulator output, resulting in a mean target stimulation intensity $(120 \%)$ of $41.8 \pm 6.8 \%$. All participants were able to reach their target stimulation intensity, averaging $2.4 \pm 3.0$ sessions ( $1.2 \pm 0.4$ days $)$ to do so, with $33 / 48$ $(68.8 \%)$ able to achieve it during their first session of treatment. Average total number of sessions was $54.1 \pm 2.9$, and mean overall treatment length, including the week gap between arTMS and tapering course, was $8.39 \pm 0.93$ weeks.

Table 3 presents the outcomes of interest. Regarding primary outcomes, response/remission rates on the $\mathrm{BDI}-\mathrm{II}$ were $25.0 \% / 16.7 \%$ post-acutely, $35.4 \% / 27.1 \%$ posttaper, and $28.6 \% / 22.9 \%$ at 1 month. Regarding secondary outcomes, scores decreased from 35.0 (9.8 SD) at baseline down to 25.8 (12.2) post-acutely, to 22.2 (13.1) post-tapering, and 21.5 (12.1) at 1 month. Percent improvement post-acutely was $27.4 \%$ (27.8\% SD), 37.9\% (33.0\%) post-tapering, and 36.1\% (34.7\%) at 1 month. On the HRSD-17, response/remission rates were $22.9 \% / 6.3 \%$ post-acutely, 58.3\%/37.5\% post-taper, and $60.0 \% / 37.1 \%$ at 1 month. Scores decreased from 23.8 (5.3 SD) at baseline down to 16.3 (6.6) post-acutely, to 12.2 (8.0) post-tapering, and $11.3(7.4)$ at 1 month. Percent improvement post-acutely was $31.4 \%$ (23.8\% SD), $48.6 \%$ (31.9\%) post-tapering, and $52.4 \%$ (28.5\%) at 1 month.

Also, since we collected daily BDI-II during treatment days, we were able to assess trajectories of outcomes, presented in Figure 5. Overall, responders showed rapid improvement during the treatment week, having achieved response on average post-acutely, and continued to show slow but steady additional improvement up to the end of the tapering course. Repeated measures ANOVA showed significant changes of BDI-II scores over time (F 2.9;85.4 = 16.6, $\mathrm{P}<$ .001) with planned contrasts revealing a significant difference between baseline and day $2(P=$ 
medRxiv preprint doi: https://doi.org/10.1101/2020.06.15.20132092; this version posted December 15, 2020. The copyright holder for this preprint (which was not certified by peer review) is the author/funder, who has granted medRxiv a license to display the preprint in perpetuity.

It is made available under a CC-BY-NC-ND 4.0 International license .

$.007)$, day 4 and $5(P=.029)$, day 5 and FU1 $(P=.013)$, as well as between FU1 and FU2 $(P=$ .002) and no significant change between other assessments. A similar pattern was observed for the HDRS-17 (F 2.2;74.1 = 68.4, $\mathrm{P}<.0001)$. There was no significant difference between response and remission rates on the BDI-II and HRSD-17 throughout all measurement times (FU1, FU2, FU3).

\section{DISCUSSION}

We present preliminary data for a novel rTMS technique optimized for widespread use. Currently, most guidelines recommend rTMS use solely in treatment-resistant depression (TRD). Specifically, the Canadian Network for Mood and Anxiety Treatments (CANMAT) recommends use in MDD participants who have failed to respond to at least 1 antidepressant (Milev et al., 2016), a decision mirrored in other international guidelines (Lefaucheur et al., 2020; Perera et al., 2016). However, access could potentially be broadened if treatments could be delivered safely in more centres, at higher volumes and lower costs, with a faster onset of response. Our study thus attempted to resolve these issues by offering several technical refinements.

First, treatment was delivered in an open-room setting, allowing one or two technicians to treat up to 4 participants in parallel, compared to the usual one-on-one approach. Even though such a setting could bring about some concerns about technician fatigue and negative patient feedback, this was not reported. We also did not observe any negative interactions between participants that could have jeopardized treatment outcome, and several participants anecdotally gave positive feedback about the more flexible scheduling of treatment sessions enabled by the open setting. Overall, this approach merits qualitative assessment with standardized feedback questionnaires for both technicians and participants. If successful on a larger scale, we believe that this approach may reduce staffing demands, increase clinic capacity and flexibility, and improve cost and accessibility. Given the current COVID-19 
medRxiv preprint doi: https://doi.org/10.1101/2020.06.15.20132092; this version posted December 15, 2020. The copyright holder for this preprint (which was not certified by peer review) is the author/funder, who has granted medRxiv a license to display the preprint in perpetuity.

It is made available under a CC-BY-NC-ND 4.0 International license .

pandemic, reduce staffing might be a potential advantage in order to observe physical distancing measures, but it would need to be conjugated with stringent infection control procedures.

One innovation that permitted such a treatment setting was the design and use of our novel AAAs. Standard articulated arms can be more expensive, while offering a limited range of motion. Our AAAs are made of widely available camera tripod equipment and have been both functional and reliable, with no material malfunctions observed. Their durable yet bendable extended branch allowed for the treatment technician to easily and accurately position the coil without tedious joint adjustments. Their anchoring to the treatment chair also eliminated any standalone equipment or cart, creating a more spacious, barrier-free clinic. The mechanical advantage of the anchoring point gives the patient the flexibility to raise or lower the incline of their treatment chair without placement adjustment, as the coil is now anchored to the shifting point of reference, thereby maintaining the coils' targeted area of focus. This custom solution decreased operational complexity, allowing for better patient care, ease of use for the technician, and more efficient use of space and equipment. Similar coil positioning equipment would be relatively straightforward for rTMS manufacturers to adopt in future.

The use of $1 \mathrm{~Hz}$ stimulation is another major component allowing for simplified rTMS delivery. Firstly, $1 \mathrm{~Hz}$ rTMS is the medically safest stimulation pattern available, having even shown anti-seizure properties in epileptic patients (Sun et al., 2012). Further, there exists empirical evidence that $1 \mathrm{~Hz}$ rTMS is better tolerated than HF protocols (Kaur et al., 2019), and also shows similar efficacy (Brunoni et al., 2017; Cao et al., 2018; Fitzgerald et al., 2019). With preliminary data potentially showing a higher safety and tolerability profile, LF $1 \mathrm{~Hz}$ could be considered in the future as a first line rTMS protocol. Beyond these factors, the greatest advantage of $1 \mathrm{~Hz}$ rTMS lies in the low cost of the equipment it requires. HF rTMS require higher-cost stimulators, with expensive cooling systems. $1 \mathrm{~Hz}$ rTMS on the other hand can be delivered on more simple stimulators with coils that do not require cooling. This setup is more 
affordable than the ones required for $\mathrm{HF}$, with the possibility of additional cost reductions in the future through higher volume use.

Parabolic coils also allow simplification of rTMS delivery. We previously published a case report on their use (Miron et al., 2019), delineating their potential advantage over Fo8 coils. Indeed, large parabolic coils may require less precise placement given their large electromagnetic field compared to the target brain region - a factor also present with larger helmet-shaped coils (Levkovitz et al., 2015). Also, their central opening allows direct visualization of underlying landmarks, resulting in easier accurate placement over the marked target. We also hypothesized that, given their possibly weaker stimulation of the DLPFC owed to the aforementioned opening, parabolic coils may function by stimulating adjacent neural substrates, such as the orbitofrontal cortex (OFC). Our group also previously published a case series on $1 \mathrm{~Hz}$ OFC, which is theorized to be involved in depression (Downar, 2019; Rao et al., 2018; Rolls, 2016).

Another novel aspect of our study was the piloting of accelerated $1 \mathrm{~Hz}$ rTMS. We are aware of only one small $(n=7)$ negative trial with limited stimulation course and duration (18 sessions over 10 days) (Tor et al., 2016). Our results are encouraging, but overall limited response and remission rates after the arTMS course would suggest that increasing the number of sessions per day and the number of pulses delivered at each session may be necessary (Baeken, 2018). Still, analyses showed a rapid effect during the accelerated phase, which supports the idea that intensive protocols with a high number of daily sessions could be an important ingredient to increase response. Indeed, a recent arTMS pilot $(n=6)$ with highly refractory MDD patients using intermittent theta-burst stimulation (iTBS), 1800 pulses/session, 10 sessions per day over 5 days, reported remission rates of 66\% (Williams et al., 2018). A larger follow-up study $(n=21)$ reported remission rates of up to $90 \%$ (Cole et al., 2020). The rapid improvement in responders post-acutely (Figure 5) is encouraging, showing that it is indeed possible to rapidly accelerate response to $1 \mathrm{~Hz}$ stimulation in some individuals. This 
medRxiv preprint doi: https://doi.org/10.1101/2020.06.15.20132092; this version posted December 15, 2020. The copyright holder for this preprint (which was not certified by peer review) is the author/funder, who has granted medRxiv a license to display the preprint in perpetuity.

It is made available under a CC-BY-NC-ND 4.0 International license .

could justify further the study of this rTMS technique in more severe inpatient cases, where suicidality is of concern and rapid response is at a premium. Overall, final outcomes post-taper compared favorably to another large trial (Blumberger et al., 2018), as well as a landmark metaanalysis (M T Berlim et al., 2012), which may be explained by the overall high number of sessions. Supporting this observation, a recent study that offered up to 21 weeks of rTMS reported remission rates of $72 \%$ (Stubbeman et al., 2018). Since there is a lack of data about 1 $\mathrm{Hz}$ arTMS alone without a subsequent tapering period, we are unable to determine the impact or the necessity of such an extension. It may well be possible that $1 \mathrm{~Hz}$ arTMS has a delayed effect, where participants would have kept on improving without the extension course, as suggested in other arTMS protocols (Sonmez et al., 2019). Conversely, high relapse rates following arTMS are also of concern (Caulfield, 2019; Williams et al., 2018).

This preliminary study has several limitations. Of primary concern is the open-label design and the absence of a sham control arm. It is to be expected that the various estimates of effectiveness might be higher than what would be obtained in a randomized, sham-controlled trial, which would represent the next logical step. In addition, the naturalistic approach of the study does not allow estimates of efficacy, but only effectiveness. Also, we did not qualitatively assess our open-room setting, as discussed previously. As a further matter, the weaker central field in the parabolic coils used may have under-stimulated the DLPFC (Miron et al., 2019); this may be correctable in future by moving the central opening to an intermediate mark between F4, Fz and Cz. Due to their less widespread use in clinical settings, results with $1 \mathrm{~Hz} r T M S$ on parabolic coils may not generalize to more commonly used Fo8 coils. The $1 \mathrm{~Hz}$ protocol used, although highly tolerable for participants, may also have been less effective due to its limited amount of pulses per session. Given that increased number of pulses has been associated with increased response in $1 \mathrm{~Hz}$ rTMS in some studies (Marcelo T Berlim et al., 2012), it may be advantageous to increase the number of pulses within the same time frame (e.g., 600 pulses in $10 \mathrm{~min})$. Finally, although we did not require participants to meet the usual requirement of TRD 
in our trial, the majority (>80\%) of participants had failed at least one adequate trial. We also did not have a minimal cut-off regarding depression severity on the mood scales for study inclusion, but average baseline scores on the BDI-Il was in the severe range. Average HRSD-17 score was also higher than in a recent large trial from our group (Blumberger et al., 2018).

Given its established efficacy in MDD and lower side-effect profile compared to medication, efforts should be made to decrease costs and complexity associated with rTMS, which could increase accessibility to the patient population. If decreased complexity can bring down costs to a level comparable to some medication regimens, the kind of techniques demonstrated here may be suitable for safe use in a wider range of settings, including more community-based approaches. If the safety, tolerability and efficacy of such protocols can be confirmed in randomized controlled trials, it is possible to imagine rTMS becoming eventually a viable first-line treatment option for MDD. 
medRxiv preprint doi: https://doi.org/10.1101/2020.06.15.20132092; this version posted December $15,2020$. The copyright holder for this preprint (which was not certified by peer review) is the author/funder, who has granted medRxiv a license to display the preprint in perpetuity.

It is made available under a CC-BY-NC-ND 4.0 International license .

\section{CONFLICTS OF INTEREST}

The authors declare no financial interests relative to this work. JPM reports research grants from the Brain \& Behavior Research Foundation NARSAD Young Investigator Award and salary support for his graduate studies from the Branch Out Neurological Foundation. HV, LF, MH, FM, SD, RZ, JS, VDJ and AMM do not report any conflict of interest. DMB receives research support from $\mathrm{CIHR}, \mathrm{NIH}$, Brain Canada and the Temerty Family through the CAMH Foundation and the Campbell Family Research Institute. He received research support and in-kind equipment support for an investigator-initiated study from Brainsway Ltd. He is the site principal investigator for three sponsor-initiated studies for Brainsway Ltd. He also receives in-kind equipment support from Magventure for investigator-initiated research. He received medication supplies for an investigator-initiated trial from Indivior. ZJD has received research and equipment in-kind support for an investigator-initiated study through Brainsway Inc and Magventure Inc. His work was supported by the Ontario Mental Health Foundation (OMHF), the Canadian Institutes of Health Research (CIHR), the National Institutes of Mental Health (NIMH) and the Temerty Family and Grant Family and through the Centre for Addiction and Mental Health (CAMH) Foundation and the Campbell Institute. FVR receives research support from CIHR, Brain Canada, Michael Smith Foundation for Health Research, Vancouver Coastal Health Research Institute, and in-kind equipment support for this investigator-initiated trial from MagVenture. He has received honoraria for participation in advisory board for Janssen. JD reports research grants from CIHR, the National Institute of Mental Health, Brain Canada, the Canadian Biomarker Integration Network in Depression, the Ontario Brain Institute, the Weston Foundation, the Klarman Family Foundation, the Arrell Family Foundation, and the Buchan Family Foundation, travel stipends from Lundbeck and ANT Neuro, in-kind equipment support for investigator-initiated trials from MagVenture, and is an advisor for BrainCheck, TMS Neuro Solutions, and Restorative Brain Clinics. 
medRxiv preprint doi: https://doi.org/10.1101/2020.06.15.20132092; this version posted December 15, 2020. The copyright holder for this preprint (which was not certified by peer review) is the author/funder, who has granted medRxiv a license to display the preprint in perpetuity. It is made available under a CC-BY-NC-ND 4.0 International license .

\section{CONTRIBUTIONS}

JPM designed the study, was responsible for data collection, analyzed the data, and wrote the manuscript. HV, LF, MH participated in the study design, data collection, and reviewed the manuscript. FM and VDJ participated in data analysis and reviewed the manuscript. participated in data collection and reviewed the manuscript. SD, RZ, JS, AM, DMB, ZJD and FVR participated in the study design and reviewed the manuscript. JD provided resources, supervised all phases of the study and reviewed the manuscript. 
medRxiv preprint doi: https://doi.org/10.1101/2020.06.15.20132092; this version posted December 15, 2020. The copyright holder for this preprint (which was not certified by peer review) is the author/funder, who has granted medRxiv a license to display the preprint in perpetuity. It is made available under a CC-BY-NC-ND 4.0 International license .

\section{ACKNOWLEDGEMENT}

JPM would like to thank the Brain \& Behavior Research Foundation and the Branch Out Neurological Foundation for their financial support of this project. We would like to thank Terri Cairo, Julian Kwok, Meaghan Todd, Nuno Ferreira, Thomas Russell and Eileen Lam for their involvement and organizational support throughout this project. This manuscript has been released as a pre-print at medRxiv (Miron et al., 2020). 


\section{REFERENCES}

Baeken, C., 2018. Accelerated rTMS: A Potential Treatment to Alleviate Refractory Depression. Front Psychol 9, 2017. https://doi.org/10.3389/fpsyg.2018.02017

Baeken, C., Vanderhasselt, M.-A., Remue, J., Herremans, S., Vanderbruggen, N., Zeeuws, D., Santermans, L., Raedt, R.D., 2013. Intensive HF-rTMS treatment in refractory medicationresistant unipolar depressed patients. J Affect Disorders 151, 625-631.

https://doi.org/10.1016/j.jad.2013.07.008

Berlim, Marcelo T, Eynde, F.V. den, Daskalakis, Z.J., 2012. Clinically Meaningful Efficacy and Acceptability of Low-Frequency Repetitive Transcranial Magnetic Stimulation (rTMS) for Treating Primary Major Depression: A Meta-Analysis of Randomized, Double-Blind and Sham-Controlled Trials. Neuropsychopharmacol 38, 543-551.

https://doi.org/10.1038/npp.2012.237

Berlim, M T, Eynde, F. van den, Daskalakis, Z.J., 2012. A systematic review and meta-analysis on the efficacy and acceptability of bilateral repetitive transcranial magnetic stimulation (rTMS) for treating major depression. Psychol Med 43, 2245-2254.

https://doi.org/10.1017/s0033291712002802

Blumberger, D., Vila-Rodriguez, F., Thorpe, K., Feffer, K., Noda, Y., Giacobbe, P., Knyahnytska, Y., Kennedy, S., Lam, R., Daskalakis, Z., Downar, J., 2018. Effectiveness of theta burst versus high-frequency repetitive transcranial magnetic stimulation in patients with depression (THREE-D): a randomised non-inferiority trial. Lancet 391, 1683-1692.

https://doi.org/10.1016/s0140-6736(18)30295-2 
Brunelin, J., Jalenques, I., Trojak, B., Attal, J., Szekely, D., Gay, A., Januel, D., Haffen, E., Schott-Pethelaz, A.-M., Brault, C., Group, S., Poulet, E., 2014. The efficacy and safety of low frequency repetitive transcranial magnetic stimulation for treatment-resistant depression: the results from a large multicenter French RCT. Brain Stimul 7, 855-863.

https://doi.org/10.1016/j.brs.2014.07.040

Brunoni, A.R., Chaimani, A., Moffa, A.H., Razza, L.B., Gattaz, W.F., Daskalakis, Z.J., Carvalho, A.F., 2017. Repetitive Transcranial Magnetic Stimulation for the Acute Treatment of Major Depressive Episodes. Jama Psychiat 74, 143-10.

https://doi.org/10.1001/jamapsychiatry.2016.3644

Cao, X., Deng, C., Su, X., Guo, Y., 2018. Response and Remission Rates Following HighFrequency vs. Low-Frequency Repetitive Transcranial Magnetic Stimulation (rTMS) Over Right DLPFC for Treating Major Depressive Disorder (MDD): A Meta-Analysis of Randomized, Double-Blind Trials. Frontiers Psychiatry 9, 1106-7. https://doi.org/10.3389/fpsyt.2018.00413

Caulfield, K.A., 2019. Is Accelerated, High-Dose Theta Burst Stimulation a Panacea for Treatment-Resistant Depression? J Neurophysiol 3, 185. https://doi.org/10.1152/jn.00537.2019

Cole, E.J., Stimpson, K.H., Bentzley, B.S., Gulser, M., Cherian, K., Tischler, C., Nejad, R., Pankow, H., Choi, E., Aaron, H., Espil, F.M., Pannu, J., Xiao, X., Duvio, D., Solvason, H.B., Hawkins, J., Guerra, A., Jo, B., Raj, K.S., Phillips, A.L., Barmak, F., Bishop, J.H., Coetzee, J.P., DeBattista, C., Keller, J., Schatzberg, A.F., Sudheimer, K.D., Williams, N.R., 2020. Stanford Accelerated Intelligent Neuromodulation Therapy for Treatment-Resistant 
Depression. Am J Psychiatry appiajp201919070720.

https://doi.org/10.1176/appi.ajp.2019.19070720

Dardenne, A., Baeken, C., Crunelle, C.L., Bervoets, C., Matthys, F., Herremans, S.C., 2018. Accelerated HF-rTMS in the elderly depressed: A feasibility study. Brain Stimul 11, 247-248. https://doi.org/10.1016/j.brs.2017.10.018

Desmyter, S., Duprat, R., Baeken, C., Autreve, S.V., Audenaert, K., Heeringen, K. van, 2016. Accelerated Intermittent Theta Burst Stimulation for Suicide Risk in Therapy-Resistant Depressed Patients: A Randomized, Sham-Controlled Trial. Front Hum Neurosci 10, 480. https://doi.org/10.3389/fnhum.2016.00480

Downar, J., 2019. Orbitofrontal Cortex: A ‘Non-rewarding’ New Treatment Target in Depression? Curr Biol 29, R59-R62. https://doi.org/10.1016/j.cub.2018.11.057

Duprat, R., Desmyter, S., Raedt, R.D., Heeringen, K. van, Abbeele, D.V. den, Tandt, H., Bakic, J., Pourtois, G., Dedoncker, J., Vervaet, M., Autreve, S.V., Lemmens, G.M.D., Baeken, C., 2016. Accelerated intermittent theta burst stimulation treatment in medication-resistant major depression_A fast road to remission? J Affect Disorders 200, 6-14.

https://doi.org/10.1016/j.jad.2016.04.015

Fitzgerald, P.B., Hoy, K.E., Elliot, D., McQueen, R.N.S., Wambeek, L.E., Daskalakis, Z.J., 2018. Accelerated repetitive transcranial magnetic stimulation in the treatment of depression. Neuropsychopharmacol 43, 1-8. https://doi.org/10.1038/s41386-018-0009-9

Fitzgerald, P.B., Hoy, K.E., Reynolds, J., Singh, A., Gunewardene, R., Slack, C., Ibrahim, S., Daskalakis, Z.J., 2019. A pragmatic randomized controlled trial exploring the relationship 
between pulse number and response to repetitive transcranial magnetic stimulation treatment in depression. Brain Stimul. https://doi.org/10.1016/j.brs.2019.09.001

George, M.S., Raman, R., Benedek, D.M., Pelic, C.G., Grammer, G.G., Stokes, K.T., Schmidt, M., Spiegel, C., DeAlmeida, N., Beaver, K.L., Borckardt, J.J., Sun, X., Jain, S., Stein, M.B., 2014. A Two-site Pilot Randomized 3 Day Trial of High Dose Left Prefrontal Repetitive Transcranial Magnetic Stimulation (rTMS) for Suicidal Inpatients. Brain Stimul 7, 421-431. https://doi.org/10.1016/j.brs.2014.03.006

Holtzheimer, P.E., McDonald, W.M., Mufti, M., Kelley, M.E., Quinn, S., Corso, G., Epstein, C.M., 2010. Accelerated repetitive transcranial magnetic stimulation for treatment-resistant depression. Depress Anxiety 27, 960-963. https://doi.org/10.1002/da.20731

Kaster, T.S., Downar, J., Vila-Rodriguez, F., Thorpe, K.E., Feffer, K., Noda, Y., Giacobbe, P., Knyahnytska, Y., Kennedy, S.H., Lam, R.W., Daskalakis, Z.J., Blumberger, D.M., 2019. Trajectories of Response to Dorsolateral Prefrontal rTMS in Major Depression: A THREE-D Study. Am J Psychiat 176, appi.ajp.2018.1-9. https://doi.org/10.1176/appi.ajp.2018.18091096

Kaur, M., Michael, J.A., Fitzgibbon, B.M., Hoy, K.E., Fitzgerald, P.B., 2019. Low-frequency rTMS is better tolerated than high-frequency rTMS in healthy people: Empirical evidence from a single session study. J Psychiatr Res 113, 79-82.

https://doi.org/10.1016/j.jpsychires.2019.03.015

Kennedy, S.H., Lam, R.W., Mclntyre, R.S., Tourjman, S.V., Bhat, V., Blier, P., Hasnain, M., Jollant, F., Levitt, A.J., MacQueen, G.M., Mclnerney, S.J., Mclntosh, D., Milev, R.V., Müller, D.J., Parikh, S.V., Pearson, N.L., Ravindran, A.V., Uher, R., Group, the C.D.W., 2016. Canadian Network for Mood and Anxiety Treatments (CANMAT) 2016 Clinical Guidelines for 
the Management of Adults with Major Depressive Disorder. Can J Psychiatry 61, 540-560. https://doi.org/10.1177/0706743716659417

Lam, R.W., Mclntosh, D., Wang, J., Enns, M.W., Kolivakis, T., Michalak, E.E., Sareen, J., Song, W.-Y., Kennedy, S.H., MacQueen, G.M., Milev, R.V., Parikh, S.V., Ravindran, A.V., Group, the C.D.W., 2016. Canadian Network for Mood and Anxiety Treatments (CANMAT) 2016 Clinical Guidelines for the Management of Adults with Major Depressive Disorder. Can J Psychiatry 61, 510-523. https://doi.org/10.1177/0706743716659416

Lefaucheur, J.-P., Aleman, A., Baeken, C., Benninger, D.H., Brunelin, J., Lazzaro, V.D., Filipović, S.R., Grefkes, C., Hasan, A., Hummel, F.C., Jääskeläinen, S.K., Langguth, B., Leocani, L., Londero, A., Nardone, R., Nguyen, J.-P., Nyffeler, T., Oliveira-Maia, A.J., Oliviero, A., Padberg, F., Palm, U., Paulus, W., Poulet, E., Quartarone, A., Rachid, F., Rektorová, I., Rossi, S., Sahlsten, H., Schecklmann, M., Szekely, D., Ziemann, U., 2020. Evidence-based guidelines on the therapeutic use of repetitive transcranial magnetic stimulation (rTMS): An update (2014-2018). Clin Neurophysiol 131, 474-528. https://doi.org/10.1016/j.clinph.2019.11.002

Levkovitz, Y., Isserles, M., Padberg, F., Lisanby, S.H., Bystritsky, A., Xia, G., Tendler, A., Daskalakis, Z.J., Winston, J.L., Dannon, P., Hafez, H.M., Reti, I.M., Morales, O.G., Schlaepfer, T.E., Hollander, E., Berman, J.A., Husain, M.M., Sofer, U., Stein, A., Adler, S., Deutsch, L., Deutsch, F., Roth, Y., George, M.S., Zangen, A., 2015. Efficacy and safety of deep transcranial magnetic stimulation for major depression: a prospective multicenter randomized controlled trial. World Psychiatry 14, 64-73. https://doi.org/10.1002/wps.20199

McClintock, S.M., Reti, I.M., Carpenter, L.L., McDonald, W.M., Dubin, M., Taylor, S.F., Cook, I.A., O’Reardon, J., Husain, M.M., Wall, C., Krystal, A.D., Sampson, S.M., Morales, O., 
Nelson, B.G., Latoussakis, V., George, M.S., Lisanby, S.H., Treatments, on behalf of both the N.N. of D.C. rTMS T.G. and the A.P.A.C. on R.T.F. on N.B. and, 2017. Consensus Recommendations for the Clinical Application of Repetitive Transcranial Magnetic Stimulation (rTMS) in the Treatment of Depression. J Clin Psychiatry 79, 1-16. https://doi.org/10.4088/jcp.16cs10905

McGirr, A., Eynde, F.V. den, Tovar-Perdomo, S., Fleck, M.P.A., Berlim, M.T., 2015.

Effectiveness and acceptability of accelerated repetitive transcranial magnetic stimulation (rTMS) for treatment-resistant major depressive disorder_An open label trial. J Affect Disorders 173, 216-220. https://doi.org/10.1016/j.jad.2014.10.068

Mendlowitz, A.B., Shanbour, A., Downar, J., Vila-Rodriguez, F., Daskalakis, Z.J., Isaranuwatchai, W., Blumberger, D.M., 2019. Implementation of intermittent theta burst stimulation compared to conventional repetitive transcranial magnetic stimulation in patients with treatment resistant depression: A cost analysis. Plos One 14, e0222546-13. https://doi.org/10.1371/journal.pone.0222546

Milev, R.V., Giacobbe, P., Kennedy, S.H., Blumberger, D.M., Daskalakis, Z.J., Downar, J., Modirrousta, M., Patry, S., Vila-Rodriguez, F., Lam, R.W., MacQueen, G.M., Parikh, S.V., Ravindran, A.V., Group, C.D.W., 2016. Canadian Network for Mood and Anxiety Treatments (CANMAT) 2016 Clinical Guidelines for the Management of Adults with Major Depressive Disorder. Can J Psychiatry 61, 561-575. https://doi.org/10.1177/0706743716660033

Miron, J.-P., Voetterl, H., Fox, L., Hyde, M., Mansouri, F., Dees, S., Zhou, R., Sheen, J., MirMoghtadaei, A., Blumberger, D.M., Daskalakis, Z.J., Vila-Rodriguez, F., Downar, J., 2020. Evaluation of a Novel Therapeutic Repetitive Transcranial Magnetic Stimulation Technique 
medRxiv preprint doi: https://doi.org/10.1101/2020.06.15.20132092; this version posted December 15, 2020. The copyright holder for this preprint (which was not certified by peer review) is the author/funder, who has granted medRxiv a license to display the preprint in perpetuity.

It is made available under a CC-BY-NC-ND 4.0 International license .

Optimized for Increased Accessibility in Major Depression. Medrxiv 2020.06.15.20132092. https://doi.org/10.1101/2020.06.15.20132092

Miron, J.-P., Voetterl, H., Mansouri, F., Blumberger, D.M., Daskalakis, Z.J., Downar, J., 2019. A case series of a novel $1 \mathrm{~Hz}$ right-sided dorsolateral prefrontal cortex rTMS protocol in major depression. Brain Stimul 13, 372-374. https://doi.org/10.1016/j.brs.2019.11.006

Perera, T., George, M.S., Grammer, G., Janicak, P.G., Pascual-Leone, A., Wirecki, T.S., 2016. The Clinical TMS Society Consensus Review and Treatment Recommendations for TMS Therapy for Major Depressive Disorder. Brain Stimul 9, 336-346.

https://doi.org/10.1016/j.brs.2016.03.010

Rao, V.R., Sellers, K.K., Wallace, D.L., Lee, M.B., Bijanzadeh, M., Sani, O.G., Yang, Y., Shanechi, M.M., Dawes, H.E., Chang, E.F., 2018. Direct Electrical Stimulation of Lateral Orbitofrontal Cortex Acutely Improves Mood in Individuals with Symptoms of Depression. Curr Biol 28, 1-25. https://doi.org/10.1016/j.cub.2018.10.026

Riedel, M., Möller, H.-J., Obermeier, M., Schennach-Wolff, R., Bauer, M., Adli, M., Kronmüller, K., Nickel, T., Brieger, P., Laux, G., Bender, W., Heuser, I., Zeiler, J., Gaebel, W., Seemüller, F., 2010. Response and remission criteria in major depression--a validation of current practice. J Psychiatr Res 44, 1063-1068. https://doi.org/10.1016/j.jpsychires.2010.03.006

Rolls, E.T., 2016. A non-reward attractor theory of depression. Neurosci Biobehav Rev 68, 4758. https://doi.org/10.1016/j.neubiorev.2016.05.007

Schulze, L., Feffer, K., Lozano, C., Giacobbe, P., Daskalakis, Z.J., Blumberger, D.M., Downar, J., 2017. Number of pulses or number of sessions? An open-label study of trajectories of 
improvement for once-vs. twice-daily dorsomedial prefrontal rTMS in major depression. Brain Stimul 11, 1-10. https://doi.org/10.1016/j.brs.2017.11.002

Sonmez, A.I., Camsari, D.D., Nandakumar, A.L., Voort, J.L.V., Kung, S., Lewis, C.P., Croarkin, P.E., 2019. Accelerated TMS for Depression: A systematic review and meta-analysis. Psychiat Res 273, 770-781. https://doi.org/10.1016/j.psychres.2018.12.041

Stubbeman, W.F., Zarrabi, B., Bastea, S., Ragland, V., Khairkhah, R., 2018. Bilateral neuronavigated $20 \mathrm{~Hz}$ theta burst TMS for treatment refractory depression: An open label study. Brain Stimul 11, 953-955. https://doi.org/10.1016/j.brs.2018.04.012

Sun, W., Mao, W., Meng, X., Wang, D., Qiao, L., Tao, W., Li, L., Jia, X., Han, C., Fu, M., Tong, X., Wu, X., Wang, Y., 2012. Low-frequency repetitive transcranial magnetic stimulation for the treatment of refractory partial epilepsy: A controlled clinical study: rTMS for the Treatment of Refractory Partial Epilepsy. Epilepsia 53, 1782-1789. https://doi.org/10.1111/j.1528-1167.2012.03626.x

Tor, P.-C., Galvez, V., Goldstein, J., George, D., Loo, C.K., 2016. Pilot Study of Accelerated Low-Frequency Right-Sided Transcranial Magnetic Stimulation for Treatment-Resistant Depression. J Ect 32, 180-182. https://doi.org/10.1097/yct.0000000000000306

Williams, N.R., Sudheimer, K.D., Bentzley, B.S., Pannu, J., Stimpson, K.H., Duvio, D., Cherian, K., Hawkins, J., Scherrer, K.H., Vyssoki, B., DeSouza, D., Raj, K.S., Keller, J., Schatzberg, A.F., 2018. High-dose spaced theta-burst TMS as a rapid-acting antidepressant in highly refractory depression. Brain 141, e18-e18. https://doi.org/10.1093/brain/awx379

Zimmerman, M., Posternak, M.A., Chelminski, I., 2004. Derivation of a definition of remission on the Montgomery-Asberg depression rating scale corresponding to the definition of remission 
medRxiv preprint doi: https://doi.org/10.1101/2020.06.15.20132092; this version posted December 15, 2020. The copyright holder for this preprint (which was not certified by peer review) is the author/funder, who has granted medRxiv a license to display the preprint in perpetuity.

It is made available under a CC-BY-NC-ND 4.0 International license .

on the Hamilton rating scale for depression. J Psychiatr Res 38, 577-582.

https://doi.org/10.1016/j.jpsychires.2004.03.007 


\begin{tabular}{ll} 
Age, years & $41.8(12.2)$ \\
Women & $56.3 \%$ \\
Education, years & $17.1(3.2)$ \\
Left-handed & $6.3 \%$ \\
Age of onset, years & $23.8(10.8)$ \\
Length of current depressive episode, months & $51.7(78.2)$ \\
Comorbid anxiety & $81.3 \%$ \\
Baseline BDI-II & $35.0(9.8)$ \\
Baseline HRSD-17 & $23.8(5.3)$ \\
Receiving psychopharmacotherapy during treatment & $70.8 \%$ \\
Antidepressant & $58.3 \%$ \\
Antidepressant combination & $22.9 \%$ \\
Antipsychotic augmentation & $14.6 \%$ \\
Lithium augmentation & $4.2 \%$ \\
Psychostimulant augmentation & $14.6 \%$ \\
Benzodiazepine & $18.8 \%$ \\
ATHF total score & $4.2(4.3)$ \\
ATHF number of trials, current episode & $1.4(1.1)$ \\
ATHF highest score & $2.6(1.6)$ \\
\hline Data are mean (SD) or number of participants (\% of total). BDI-II \\
= Beck Depression Inventory-II, HRSD-17 = 17-item Hamilton \\
Rating Scale for Depression, ATHF = Antidepressant Treatment \\
History Form. \\
\hline Table 1: Baseline demographic and clinical characteristics (n = \\
48)
\end{tabular}


medRxiv preprint doi: https://doi.org/10.1101/2020.06.15.20132092; this version posted December 15, 2020. The copyright holder for this preprint (which was not certified by peer review) is the author/funder, who has granted medRxiv a license to display the preprint in perpetuity.

It is made available under a CC-BY-NC-ND 4.0 International license .

\begin{tabular}{ll}
\hline Serious AE & $0 / 48(0.0 \%)$ \\
\hline AE total & $19 / 48(39.6 \%)$ \\
Headache & $11 / 48(22.9 \%)$ \\
Fatigue & $7 / 48(14.6 \%)$ \\
Nausea & $2 / 48(4.2 \%)$ \\
Scalp tenderness & $3 / 48(4.2 \%)$ \\
Hand twitching & $1 / 48(2.1 \%)$ \\
Insomnia & $3 / 48(6.3 \%)$ \\
Dizziness & $1 / 48(2.1 \%)$ \\
Anxiety & $3 / 48(6.3 \%)$ \\
Jaw pain & $1 / 48(2.1 \%)$ \\
Visual symptoms & $1 / 48(2.1 \%)$ \\
First treatment pain VRS & $5.6(2.0)$ \\
Last treatment pain VRS & $1.9(1.9)$ \\
Number of days to reach target stimulation intensity & $3.8(6.3)$ \\
\hline Number of participants $(n=48)$ reporting adverse events $(A E-\%)$. For \\
pain, data mean (SD). VRS = Verbal Rating Scale. \\
\hline
\end{tabular}

Table 2: Adverse events 


\begin{tabular}{ll}
\hline BDI-II & \\
\hline Response post-acute & $12 / 48(25.0 \%)$ \\
Response post-taper & $17 / 48(35.4 \%)$ \\
Response 1-month & $10 / 35(28.6 \%)$ \\
Remission post-acute & $8 / 48(16.7 \%)$ \\
Remission post-taper & $13 / 48(27.1 \%)$ \\
Remission 1-month & $8 / 35(22.9 \%)$ \\
Score baseline & $35.0(9.8)$ \\
Score change post-acute & $25.8(12.2)$ \\
Score change post-taper & $22.2(13.1)$ \\
Score change 1-month & $21.5(12.1)$ \\
Percent improvement post-acute & $27.4 \%(27.8 \%)$ \\
Percent improvement post-taper & $37.9 \%(33.0 \%)$ \\
Percent improvement 1-month & $36.1 \%(34.7 \%)$ \\
\hline HRSD-17 & \\
\hline Response post-acute & $11 / 48(22.9 \%)$ \\
Response post-taper & $28 / 48(58.3 \%)$ \\
Response 1-month & $21 / 35(60.0 \%)$ \\
Remission post-acute & $3 / 48(6.3 \%)$ \\
Remission post-taper & $18 / 48(37.5 \%)$ \\
Remission 1-month & $13 / 35(37.1 \%)$ \\
Score baseline & $23.8(5.3)$ \\
Score change post-acute & $16.3(6.6)$ \\
Score change post-taper & $12.2(8.0)$ \\
Score change 1-month & $11.3(7.4)$ \\
Percent improvement post-acute & $31.4 \%(23.8 \%)$ \\
Percent improvement post-taper & $48.6 \%(31.9 \%)$ \\
Percent improvement 1-month & $52.4 \%(28.5 \%)$ \\
\hline Data are mean (SD). For remission and response rates, data are $\mathrm{n}(\%$ of \\
participants assessed). BDI-II = Beck Depression Inventory-II,, $\mathrm{HRSD}-17=17-$ \\
item Hamilton Rating Scale for Depression. & \\
\hline Table 3: Outcomes of & \\
\hline
\end{tabular}

Table 3: Outcomes of interest 
medRxiv preprint doi: https://doi.org/10.1101/2020.06.15.20132092; this version posted December 15, 2020. The copyright holder for this preprint (which was not certified by peer review) is the author/funder, who has granted medRxiv a license to display the preprint in perpetuity.

It is made available under a CC-BY-NC-ND 4.0 International license .

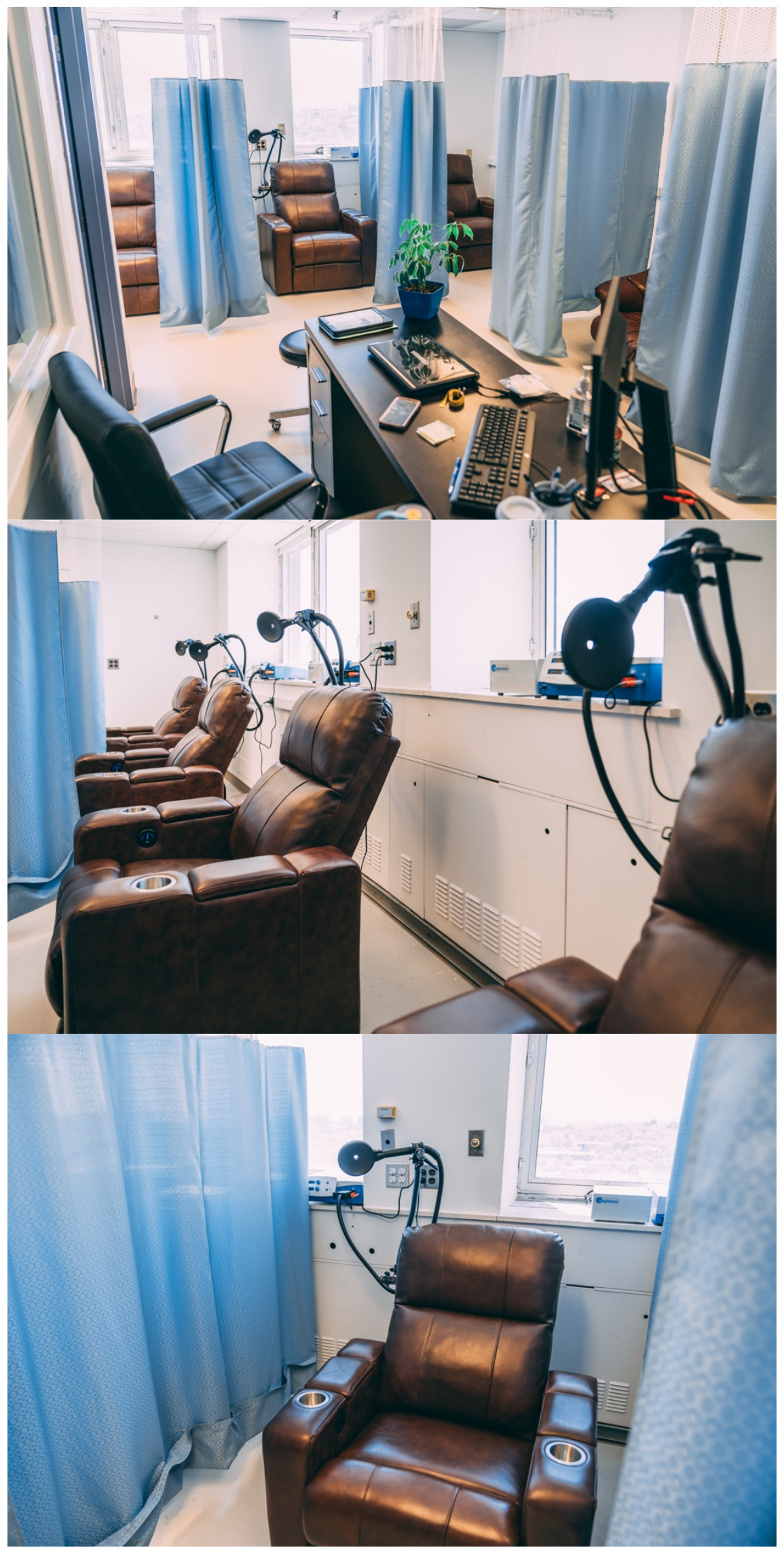

Figure 1: Clinical setup - 4 recliners equipped with AAAs holding rTMS coils, connected to the rTMS stimulators. Treatment was delivered in an open room setting, allowing up to 4 participants to receive treatment simultaneously, with the help of one or two technicians. $A A A=$ Anchored Articulating Arm 


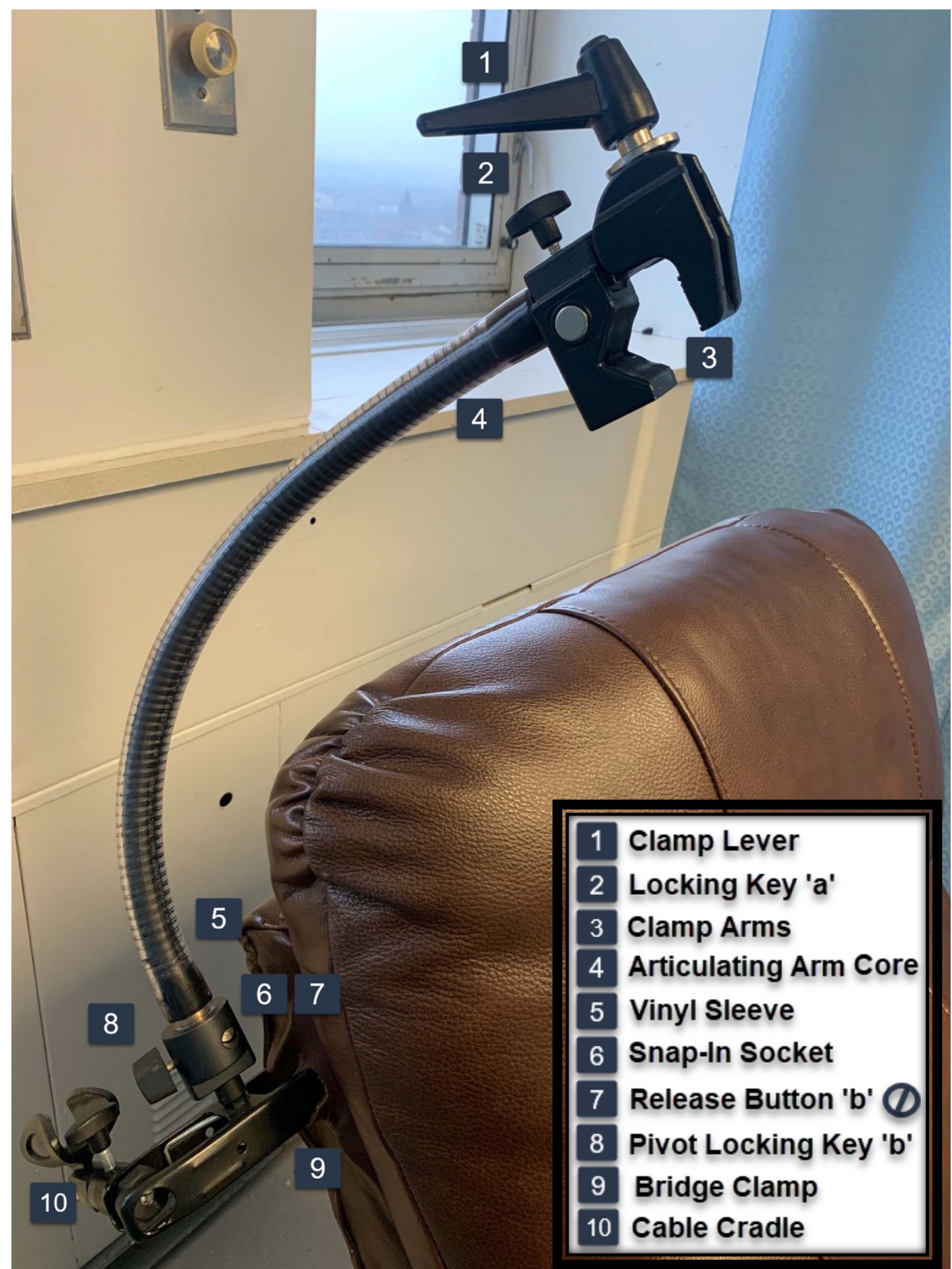

Figure 2: Anchored Articulating Arm (AAA) schematic - AAAs are made out of inexpensive camera tripod equipment and are anchored at their base to the corner of the treatment chair. Coils are held securely by a clamp locking it to the AAA, maintaining position until treatment has been completed, at which time they can be quickly twisted out of the way. 
medRxiv preprint doi: https://doi.org/10.1101/2020.06.15.20132092; this version posted December 15, 2020. The copyright holder for this

preprint (which was not certified by peer review) is the author/funder, who has granted medRxiv a license to display the preprint in perpetuity.

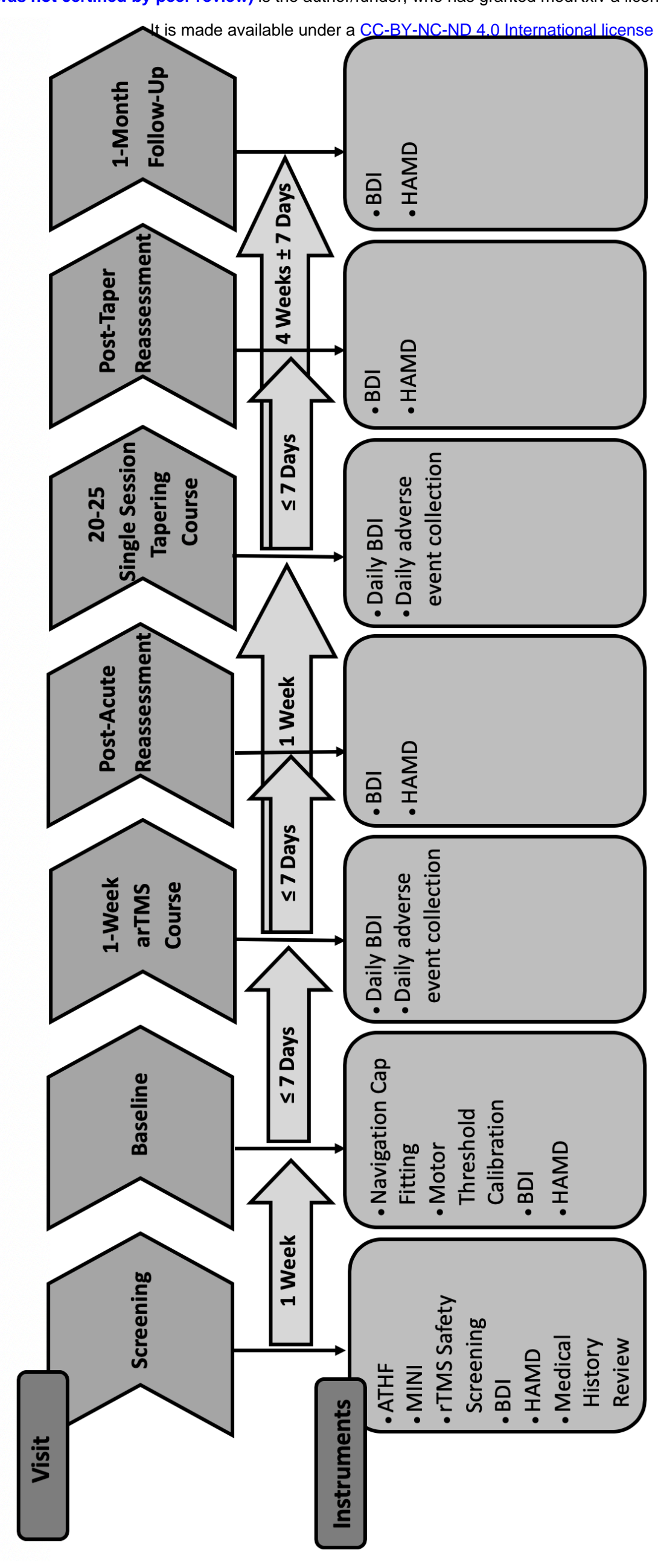

ले

क कิ की

ट ट

两要

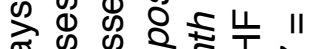

定

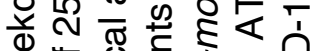

\ن

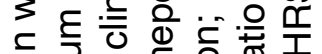

으 르 $\sigma$.

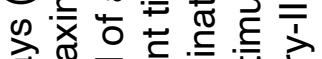
สิ ซ 원에 क त क क

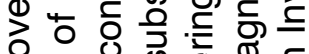
E ठ के ळ

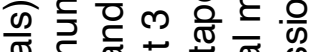
$>$ 든 ब. . क ᄃ 0 : 을 क

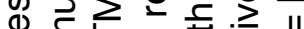
की 屯 . . 흥 흔 은 인

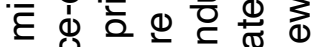

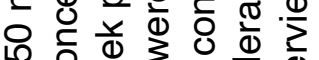
象 0 \& 3 Q

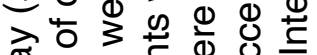

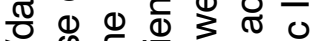
के 등ㅎㅇ 뭉 क क 음 응 흥

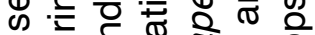

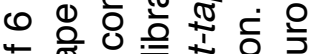

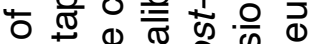
() क人 응 क क क $\frac{1}{5}$ \% $\sum$ 잉

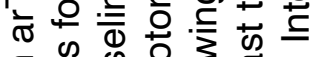
ᄃ ๙ ○心

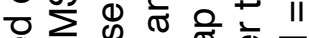

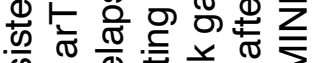
क ब声市分

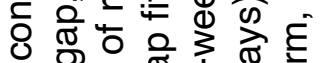

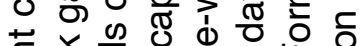

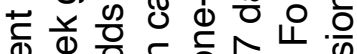
ह $\sum^{\infty} 0$ 은 है ब

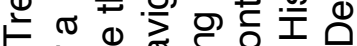
, ఫ

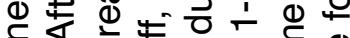
잉 ह क क क

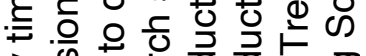

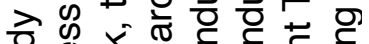
을 Ð ๗ 0 \ ஸं ल ट व के ब

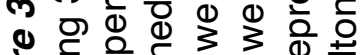

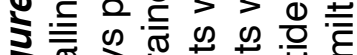

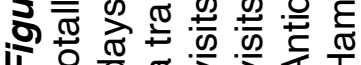

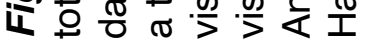


medRxiv preprint doi: https://doi.org/10.1101/2020.06.15.20132092; this version posted December 15, 2020. The copyright holder for this preprint (which was not certified by peer review) is the author/funder, who has granted medRxiv a license to display the preprint in perpetuity.

It is made available under a CC-BY-NC-ND 4.0 International license .

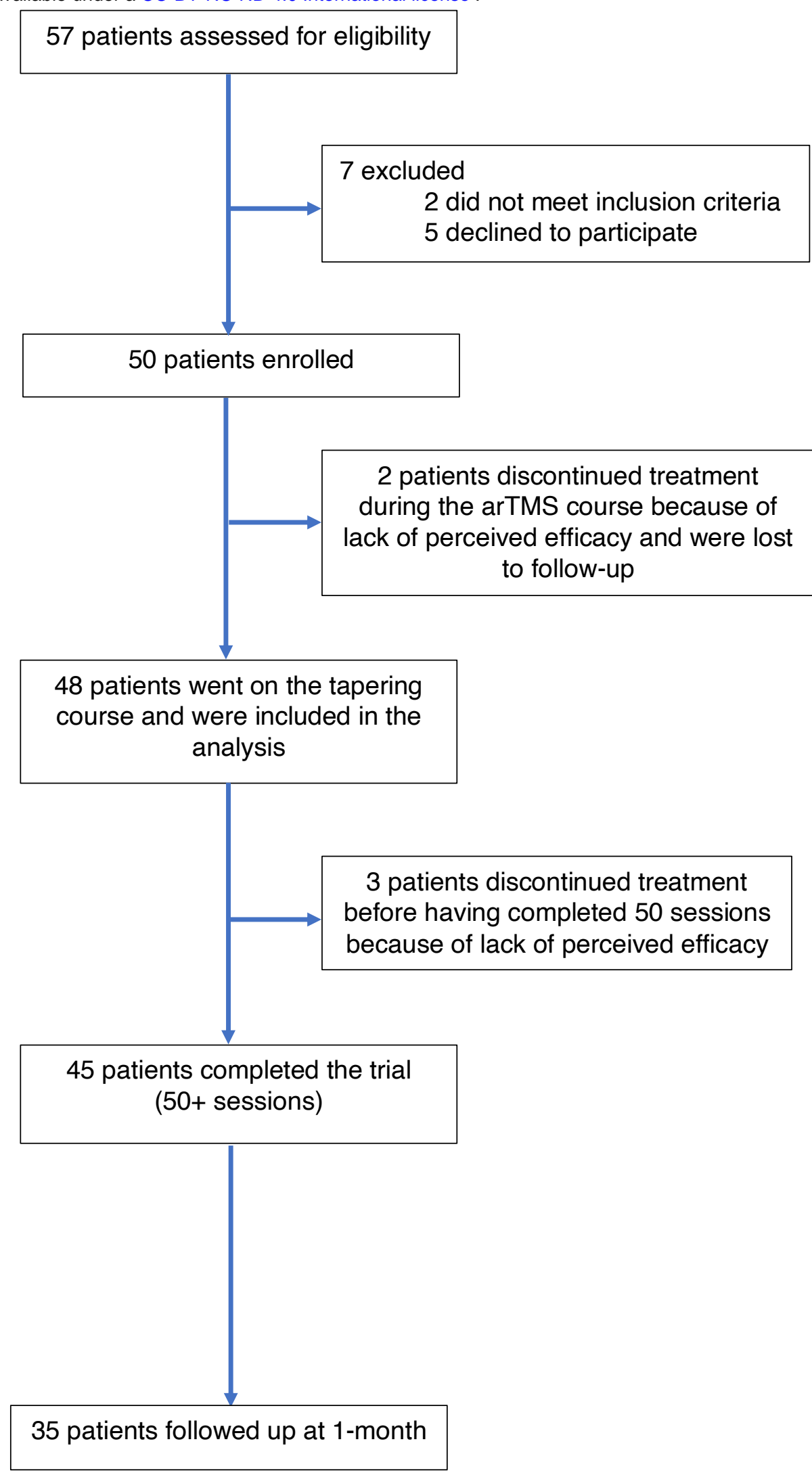

Figure 4: Trial CONSORT flow diagram - arTMS = accelerated repetitive transcranial magnetic stimulation. 
medRxiv preprint doi: https://doi.org/10.1101/2020.06.15.20132092; this version posted December 15, 2020. The copyright holder for this preprint (which was not certified by peer review) is the author/funder, who has granted medRxiv a license to display the preprint in perpetuity.

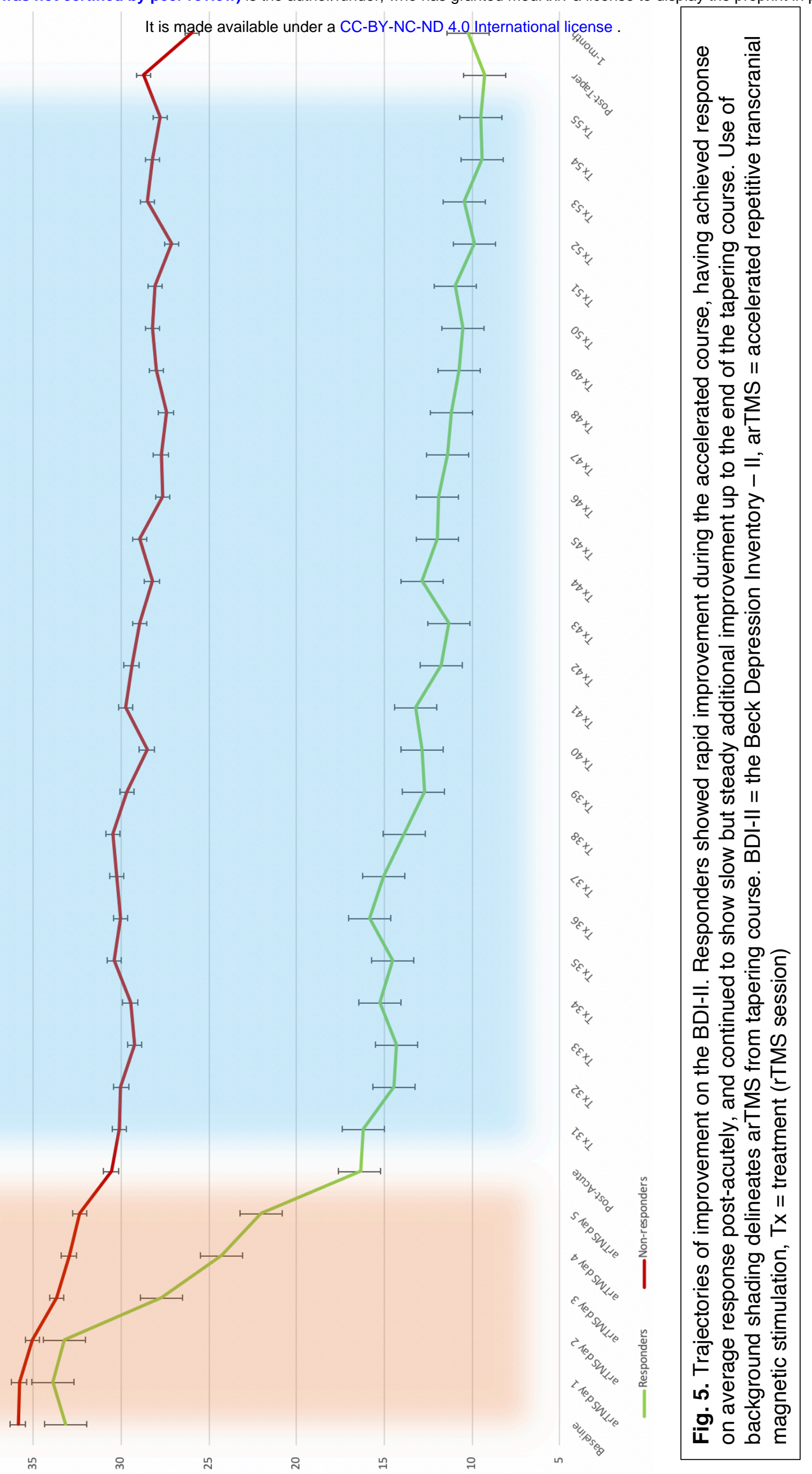

